\title{
COMUNICAÇÃO
}

\section{SUBSTRATOS NO DESENVOLVIMENTO INICIAL DE QUATRO CULTIVARES DE PESSEGUEIRO E UMA NECTARINEIRA}

\author{
Substrates in the initial production of four peach varieties and one nectarine variety seedlings \\ Américo Wagner Júnior ${ }^{1}$, Jacson Rondinelli da Silva Negreiros ${ }^{2}$, Rodrigo Sobreira Alexandre', \\ Leonardo Duarte Pimentel ${ }^{3}$, Marcos Antônio Dell'orto Morgado ${ }^{4}$, Claudio Horst Bruckner ${ }^{1}$
}

\begin{abstract}
RESUMO
Entre os fatores que contribuem para melhor desenvolvimento inicial das plantas, estão a qualidade da semente e o substrato utilizado.Objetivou-se avaliar o efeito do substrato na formação inicial de pessegueiro e nectarineira. $\mathrm{O}$ trabalho foi realizado no Departamento de Fitotecnia, da Universidade Federal de Viçosa, de fevereiro a março de 2004. Foram utilizados quatro cultivares de pessegueiro, 'Alô Doçura', 'Campinas 1', 'Relíquia' e 'Ouromel' e uma cultivar de nectarineira 'Josefina'. Sementes retiradas de frutos maturos, foram estratificadas em câmara fria, com temperatura de $5 \pm 1^{\circ} \mathrm{C}$ e ausência de luz. Após a germinação, no interior da casa-de-vegetação, procedeu-se à semeadura em recipientes plásticos (3 litros), contendo os substratos: Plantmax ${ }^{\circledR} ;$ Plantmax $®+$ Areia (1:1 v/v); Plantmax ${ }^{\circledR}+$ Latossolo Vermelho (1:1 v/v); Plantmax ${ }^{\circledR}+$ Latossolo Vermelho + Areia (1:1:1 v/v). Foi utilizado o delineamento experimental inteiramente casualizado, num fatorial 5 x 4 (cultivar x substrato), com cinco repetições, considerando-se como unidade experimental cada recipiente plástico. Após 38 dias da semeadura foram analisadas: porcentagem de emergência, número de folhas, comprimento total, altura e comprimento de raiz, diâmetro do caule, massa da matéria seca total, da parte aérea e da raiz e o número de brotações primárias. O substrato teve efeito no desenvolvimento inicial de pessegueiro, obtendo-se os melhores resultados com o substrato comercial Plantmax ${ }^{\circledR}$. O maior acúmulo de massa de matéria seca total e da parte aérea foi obtido com os cultivares 'Campinas 1' e 'Relíquia', sendo que esse último, também proporcionou maior número de brotações primárias.
\end{abstract}

Termos para indexação: Prunus sp., crescimento, germinação.

\begin{abstract}
Among the factors that contribute for the best initial plants growing are seed quality and substrate utilized. The aim of this work was to evaluate the effect of substrate on the initial production peach and nectarine seedlings. The work was carried out in the Department of Plant Science of the Universidade Federal de Viçosa, State of Minas Gerais (Brazil), from February to March, 2004. In this work four peach varieties were used: 'Alô Doçura ', 'Campinas 1 ', 'Relíquia ' and 'Ouromel ' and a nectarine variety, 'Josefina'. Seeds from mature fruits were stratified in a dark cold room, at a constant temperature of $5 \pm 1^{\circ} \mathrm{C}$. After germination, the material was transferred to a greenhouse. The germinated seeds were sowed in plastic bags ( 3 liters), using the substrates Plantmax ${ }^{\circledR}$; Plantmax ${ }^{\circledR}+$ Sand $(1: 1 \mathrm{v} / \mathrm{v})$; Plantmax ${ }^{\circledR}+$ Red Soil $(1: 1 \mathrm{v} / \mathrm{v})$; Plantmax ${ }^{\circledR}+$ Red 'Latossolo' + Sand $(1: 1: 1 \mathrm{v} / \mathrm{v})$. The experiment was carried out in an entirely randomized design, in a factorial 5 x 4 (varieties x substrate), with five replications and each plastic bag considered as a plot. 38 days after of sowing, the percentage of emergence, number of leaves, total length, height and root length, diameter of the stem, total dry matter, aerial part and root dry matter and the number of primary ramifications were evaluated. The substrate had effect on initial peach seedling growth and the best results were obtained with the commercial substrate Plantmax ${ }^{\circledR}$. The largest accumulation of dry matter and total and aerial part was obtained with 'Campinas 1 ' and 'Relíquia ' varieties and the last one provided larger number of primary ramifications.
\end{abstract}

Index Terms: Prunus sp., growth, germination.

(Recebido em 29 de março de 2006 e aprovado em 26 de março de 2007)

O consumo mundial de frutas frescas cresce a uma taxa de 5\% ao ano, aumento também verificado no Brasil. Para competir nesse mercado, é necessário um produto de qualidade e com preço competitivo, obtido por meio do aumento da produtividade dos pomares (FACHINELLO, 2000).

\footnotetext{
${ }^{1}$ Engenheiros Agrônomos, Doutores - Departamento de Fitotecnia - Universidade Federal de Viçosa/UFV - Campus Universitário, s/n - 36570-000 Viçosa, MG - americowagner@ibest.com.br; rsalexandre@click21.com.br; bruckner@ufv.br - Bolsista CAPES

Engenheiro Agrônomo, Doutor em Genética e Melhoramento - Universidade Federal do Acre/UFAC - Campus Universitário Reitor Aulio Gelio Alves de Souza, Rodovia Br 364, Km 04 - Distrito Industrial - Cx. P. 500 - 69915-900 - Rio Branco, AC - jacsonrn@gmail.com

${ }^{3}$ Engenheiro Agrônomo, Doutorando em Fitotecnia - Departamento de Fitotecnia - Universidade Federal de Viçosa/UFV - Campus Universitário, s/n 36570-000 - Viçosa, MG - agropimentel@yahoo.com.br - Bolsista CNPq

${ }^{4}$ Mestrando em Fitotecnia - Departamento de Fitotecnia - Universidade Federal de Viçosa/UFV - Campus Universitário, s/n - $36570-000$ - Viçosa, MG dell.orto@bol.com.br
} 
Nesse sentido, o aumento na disponibilidade de mudas de qualidade e de menor custo aos fruticultores é essencial para ampliação de pomares e, conseqüentemente, aumento da produção de frutas no Brasil (TOFANELLI et al., 2003).

A propagação convencional do pessegueiro se resume basicamente à enxertia do cultivar copa sobre portaenxertos provenientes de sementes (CHALFUN et al., 1998). Os porta-enxertos de prunóideas usados no Brasil são obtidos a partir de caroços de cultivares copa obtidos junto às indústrias conserveiras, estabelecidas nos pólos de produção ou de cultivares específicos destinados a porta-enxertos, como 'Okinawa'.

Fachinello et al. (1995), descrevem que para obtenção de porta-enxerto podem ser utilizadas sementes de qualquer cultivar que apresente boa adaptabilidade na região de cultivo do pomar. Além disso, entre os métodos de melhoramento mais aplicados nessa cultura, destaca-se a hibridação, seguida pelo plantio das sementes originadas desse processo, geralmente, em condições adensadas, possibilitando posteriormente, a seleção de indivíduos geneticamente superiores na população segregante.

Em ambos os casos, tanto na propagação de mudas como no melhoramento genético, é importante a rápida germinação e crescimento das plantas para reduzir o tempo e o custo de formação delas.

É necessário que as sementes de pessegueiro passem por um período de estratificação para superação da dormência fisiológica, sendo que com o início da germinação, procede-se o plantio dessas sementes germinadas em recipientes plásticos, canteiros (sementeiras) ou diretamente nas linhas dos viveiros (FINARDI, 1998).

A estratificação pode ser realizada de forma natural a campo, em locais de inverno frio, ou de maneira artificial, como predomina no Sudeste (Barbosa et al., 1993). Apesar da obtenção de altos porcentuais de germinação quando se realiza a estratificação diretamente no campo, normalmente, as plantas oriundas desse processo apresentam crescimento inicial desuniforme (BARBOSA et al., 1987).

Além disso, na região Sudeste é praticamente obrigatório submeter as sementes de pessegueiro ao processo de estratificação artificial, uma vez que, normalmente, a quantidade de frio não é suficiente para a quebra natural da endodormência. A submissão das sementes a frio artificial também favorece a germinação mais rápida e uniforme do material (SEELEY et al., 1998).

$\mathrm{O}$ rápido desenvolvimento da planta depende também de outros fatores, entre os quais está a utilização de sementes de boa qualidade e a escolha do melhor substrato (WAGNER JÚNIOR et al., 2006).

Entende-se por substrato qualquer material que é usado com a finalidade de servir de base para o desenvolvimento de uma planta até a sua transferência para o viveiro, ou para a área de produção, podendo ser compreendido não apenas como suporte físico, mas também como fornecedor de nutrientes para a muda em formação (FERMINO, 1996; KÄMPF, 2000).

Um bom substrato é aquele que proporciona condições adequadas à germinação e ao desenvolvimento do sistema radicular da planta em formação (RAMOS et al., 2002). Toledo (1992) acrescenta que um bom substrato deve ser de baixa densidade, equilibrada composição química e física, elevada CTC, boa capacidade de aeração e drenagem, boa coesão entre as partículas e adequada aderência junto às raízes.

Entretanto, a escolha do material a ser utilizado não depende somente dessas características, mas também da disponibilidade e do custo de aquisição (KÄMPF, 1992).

O Plantmax $®$ é um substrato comercial elaborado com vermiculita expandida e materiais orgânicos de origem vegetal, isento de pragas, microrganismos e sementes de invasoras. A areia é um material considerado quimicamente inerte, de fácil obtenção, excelente drenagem, sendo útil em misturas como condicionador físico e para germinação de sementes (RAMOS et al., 2002). A associação de materiais, especialmente em mistura com o solo, permite melhorar as condições para o desenvolvimento inicial das plantas.

Hartmann et al. (1990) aconselham misturar ao solo areia e materiais orgânicos, como forma de melhorar a textura e criar melhores condições para o desenvolvimento das mudas.

Objetivou-se neste trabalho avaliar o efeito do substrato no desenvolvimento inicial de mudas de quatro cultivares de pessegueiro e uma nectarineira.

O trabalho foi realizado no Departamento de Fitotecnia, da Universidade Federal de Viçosa, sendo utilizados as cultivares de pessegueiro 'Alô Doçura', 'Campinas 1', 'Relíquia' e 'Ouromel' e a cultivar de nectarineira 'Josefina'.

Frutos obtidos por polinização livre, desses cultivares, apresentando estádio de maturação em ponto de colheita foram colhidos e, em seguida despolpados manualmente, retirando-se toda a polpa aderida. Imediatamente após a despolpa, os endocarpos foram quebrados manualmente para obtenção das sementes, com auxílio de uma morsa.

Após a extração, as sementes foram desinfestadas com solução fungicida (Benlate $500-15 \mathrm{~g} \mathrm{~L}^{-1}$ ) e colocadas 
em sacos plásticos, individuais, contendo papel germtest embebido com a mesma solução fungicida usada no processo de desinfestação. Em seguida, os sacos plásticos foram selados, colocados em envelopes de papel pardo e acondicionados em câmara fria a $5 \pm 1{ }^{\circ} \mathrm{C}$, sob ausência de luz. Todas as sementes foram extraídas e colocadas em câmara fria na mesma data, sendo que o número de horas necessárias para germinação encontra-se na Tabela 1.

Tabela 1 - Unidades de frio acumulado para germinação de $100 \%$ das sementes de quatro cultivares de pessegueiro e uma cultivar de nectarineira, segundo método de Utah (RICHARDSON et al., 1974).

\begin{tabular}{cc}
\hline Cultivar & Unidades de frio \\
\hline 'Alô Doçura' & 1126 \\
'Campinas 1' & 922 \\
'Ouromel' & 1204 \\
'Relíquia' & 1492 \\
'Josefina' & 1126 \\
\hline
\end{tabular}

Com a germinação, todo o material foi retirado da câmara fria e no interior da casa de vegetação procedeu-se à semeadura em recipiente plástico com capacidade de 3 litros (32 cm x $16 \mathrm{~cm}$ litros), a 1,0 cm de profundidade, contendo os substratos Plantmax ${ }^{\circledR}$; Plantmax ${ }^{\circledR}+$ Areia $(1: 1 \mathrm{v} / \mathrm{v})$; Plantmax ${ }^{\circledR}+$ Latossolo Vermelho $(1: 1 \mathrm{v} / \mathrm{v})$ e Plantmax ${ }^{\circledR}+$ Latossolo Vermelho + Areia (1:1:1 v/v), cujas características químicas apresentam-se na Tabela 2 . A irrigação foi realizada diariamente de forma manual.

Foi utilizado o delineamento experimental inteiramente casualizado, num fatorial $5 \times 4$ (cultivar $\mathrm{x}$ substrato), com cinco repetições, considerando-se como unidade experimental, cada recipiente plástico.

As avaliações foram realizadas aos 38 dias após a instalação do experimento. As variáveis analisadas foram: porcentagem de emergência, número de folhas, comprimento total, altura e comprimento de raiz das plantas (cm), diâmetro do caule (mm), massa da matéria seca total, da parte aérea e das raízes das plantas (g) e o número de brotações primárias.

Para determinação do comprimento total, altura e comprimento de raiz, as mudas foram retiradas dos substratos, cuidadosamente, lavadas em água e medidas com auxílio de uma régua graduada em centímetros. $\mathrm{O}$ diâmetro do caule foi medido com paquímetro digital, na altura do colo das plantas. O sistema radicular e a parte aérea foram secos em estufa de circulação forçada a $60^{\circ} \mathrm{C}$, até peso constante, obtido em 72 horas, para posterior determinação do valor da massa da matéria seca do sistema radicular e da parte aérea, sendo realizada a pesagem em balança analítica.

As temperaturas do ar, mínima e máxima foram obtidas diariamente no interior da casa de vegetação, sendo as médias de $21,78^{\circ} \mathrm{C}, 18,49^{\circ} \mathrm{C}$ e $27,40^{\circ} \mathrm{C}$, respectivamente.

Os dados foram submetidos à análise de variância e ao teste de Tukey $(\alpha=0,05)$, sendo que os dados em porcentagem foram transformados previamente em arco seno $\sqrt{\mathrm{x} / 100}$ e o número de folhas e de brotações primárias em $\sqrt{\mathrm{x}+1}$. Já os demais dados não sofreram transformação. Foi utilizado o aplicativo computacional SANEST (ZONTA \& MACHADO, 1984).

Não foram encontradas diferenças significativas pelo teste de $\mathrm{F}$, na interação cultivar $\mathrm{x}$ substrato, nas variáveis analisadas. Entretanto, detectou-se efeito dos substratos em quase todas as variáveis analisadas, com exceção da porcentagem de emergência, comprimento de raiz e massa da matéria seca das raízes (Tabela 3 ).

Segundo Pereira et al. (2002), quando se utilizam sementes que estão em fase inicial de germinação, com emissão da radícula, a emergência das novas plantas ocorre em menos de uma semana e atinge índices de sobrevivência superiores a $90 \%$. Os resultados obtidos no presente trabalho estão de acordo com essa observação, no qual, observou-se a emergência das plantas, nos substratos e cultivares, durante a primeira semana de implantação do experimento, com índices de sobrevivência superiores a 97\% (Tabelas 3 e 4).

As plantas cultivadas no substrato comercial Plantmax ${ }^{\circledR}(\mathrm{S} 1)$ apresentaram as maiores médias na massa de matéria seca total e da parte aérea das plantas, número de brotações primárias e de folhas, sendo que nessa última, a média não diferiu significativamente do substrato S2 (Tabela 3).

Acredita-se que isso se deve, provavelmente, às características químicas que esse substrato possui. Observando-se os resultados obtidos na Tabela 2, comprovou-se que esse apresentou os maiores valores em relação à composição química, com valores expressivos de $\mathrm{P}$ e $\mathrm{K}$, que são os macronutrientes, juntamente com nitrogênio, mais requeridos pelo pessegueiro (FREIRE \& MAGNANI, 1998) e, necessários para bom desempenho das plantas.

Além disso, pode ser verificada certa correspondência entre os resultados do número de folhas e o ganho de massa de matéria seca das plantas entre os substratos. Segundo Larcher (2000), grande parte da matéria seca acumulada pelas plantas durante o 
Tabela 2 - Características químicas de quatro substratos utilizados na formação de porta-enxertos para pessegueiro.

\begin{tabular}{ccccccccccccc}
\hline \multirow{2}{*}{ Substrato $^{\mathrm{a}}$} & $\mathrm{pH}$ & \multicolumn{1}{c}{$\mathrm{P}$} & $\mathrm{K}$ & $\mathrm{Ca}^{2+}$ & $\mathrm{Mg}^{2+}$ & $\mathrm{Al}^{3+}$ & $\mathrm{H}+\mathrm{Al}$ & $\mathrm{SB}$ & $\mathrm{CTC}(\mathrm{t})$ & $\mathrm{CTC}(\mathrm{T})$ & $\mathrm{V}$ \\
\cline { 2 - 12 } & \multicolumn{1}{c}{$\mathrm{H}_{2} \mathrm{O}$} & \multicolumn{2}{c}{$\mathrm{mg} \mathrm{dm}^{-3}$} & & \multicolumn{7}{c}{$\mathrm{cmolc} \mathrm{dm}^{-3}$} \\
\hline $\mathrm{S} 1$ & 5,47 & 662,1 & 600 & 9,64 & 3,95 & 0,0 & 6,9 & 15,12 & 15,12 & 22,02 & 68,7 \\
$\mathrm{~S} 2$ & 5,5 & 115,1 & 210 & 4,0 & 1,7 & 0,0 & 6,60 & 6,24 & 6,24 & 12,84 & 49,0 \\
$\mathrm{~S} 3$ & 6,1 & 104,9 & 250 & 5,0 & 1,7 & 0,0 & 4,62 & 7,34 & 7,34 & 11,96 & 61,0 \\
$\mathrm{~S} 4$ & 5,7 & 92,0 & 270 & 5,7 & 2,0 & 0,0 & 7,26 & 8,39 & 8,39 & 15,65 & 54,0 \\
\hline
\end{tabular}

${ }^{\mathrm{a}}(\mathrm{S} 1)$ Plantmax ${ }^{\circledR}$; (S2) Plantmax ${ }^{\circledR}+$ Areia - 1:1 v/v; (S3) Plantmax ${ }^{\circledR}+$ Latossolo Vermelho - 1:1 v/v; (S4) Plantmax ${ }^{\circledR}+$ Latossolo Vermelho + Areia - 1:1:1 v/v.

Tabela 3 - Médias de porcentagem de emergência (EM), número de folhas (NF), comprimento total (CT), altura de planta (AP), comprimento de raiz (CR), diâmetro do caule (DC), massa da matéria seca total (MMST), massa da matéria seca da parte aérea (MMSPA), massa da matéria seca de raiz (MMSR) e número de brotações primárias (NBP), em quatro substratos.

\begin{tabular}{|c|c|c|c|c|c|c|c|c|c|c|}
\hline Substrato $^{\mathrm{a}}$ & $\begin{array}{l}\mathrm{EM} \\
(\%)\end{array}$ & $\mathrm{NF}$ & $\begin{array}{l}\mathrm{CT} \\
(\mathrm{cm})\end{array}$ & $\begin{array}{l}\text { AP } \\
(\mathrm{cm})\end{array}$ & $\begin{array}{c}\mathrm{CR} \\
(\mathrm{cm})\end{array}$ & $\begin{array}{c}\mathrm{DC} \\
(\mathrm{mm})\end{array}$ & $\begin{array}{c}\text { MMST } \\
(\mathrm{g})\end{array}$ & $\begin{array}{c}\text { MMSPA } \\
(\mathrm{g})\end{array}$ & $\begin{array}{c}\text { MMSR } \\
(\mathrm{g})\end{array}$ & NBP \\
\hline $\mathrm{S} 1$ & $100,0 \mathrm{~ns}$ & $101,15 \mathrm{a}^{*}$ & $62,04 \mathrm{a}$ & $38,29 a$ & $23,75 \mathrm{~ns}$ & $3,00 \mathrm{a}$ & $1,91 \mathrm{a}$ & $1,73 \mathrm{a}$ & $0,18 \mathrm{~ns}$ & $10,7 \mathrm{a}$ \\
\hline S2 & 99,61 & $79,61 \mathrm{ab}$ & $63,97 \mathrm{a}$ & $38,35 \mathrm{a}$ & 25,62 & $2,80 \mathrm{a}$ & $1,45 b$ & $1,29 b$ & 0,16 & $7,04 \mathrm{~b}$ \\
\hline S3 & 98,42 & $60,67 b$ & $55,06 \mathrm{ab}$ & $34,54 a$ & 20,52 & $2,51 \mathrm{ab}$ & $1,19 b$ & $1,09 \mathrm{~b}$ & 0,10 & $4,57 \mathrm{c}$ \\
\hline S4 & 98,43 & $33,03 \mathrm{c}$ & $50,70 \mathrm{~b}$ & $27,62 b$ & 23,08 & $2,14 b$ & $0,52 \mathrm{c}$ & $0,42 \mathrm{c}$ & 0,10 & $0,92 \mathrm{~d}$ \\
\hline $\mathrm{CV}(\%)$ & 23,54 & 23,02 & 25,35 & 25,40 & 29,17 & 25,28 & 43,40 & 45,47 & 83,93 & 23,50 \\
\hline
\end{tabular}

${ }^{\mathrm{a}}(\mathrm{S} 1)$ Plantmax ${ }^{\circledR} ;(\mathrm{S} 2)$ Plantmax ${ }^{\circledR}+$ Areia - 1:1 v/v; (S3) Plantmax ${ }^{\circledR}+$ Latossolo Vermelho - 1:1 v/v; (S4) Plantmax ${ }^{\circledR}+$ Latossolo Vermelho + Areia $-1: 1: 1 \mathrm{v} / \mathrm{v}$.

ns. Não significativo pelo teste $F$.

*Letras diferentes na mesma coluna diferem significativamente ao nível de 5\% de probabilidade pelo teste de Tukey.

Tabela 4 - Médias de porcentagem de emergência (EM), número de folhas (NF), comprimento total (CT), altura de planta (AP), comprimento de raiz (CR), diâmetro do caule (DC), massa da matéria seca total (MMST), massa da matéria seca da parte aérea (MMSPA), massa da matéria seca de raiz (MMSR) e número de brotações primárias (NBP), de quatro cultivares de pessegueiro e um cultivar de nectarineira.

\begin{tabular}{lllllllllll}
\hline \multicolumn{1}{c}{ Cultivar } & $\mathrm{EM} \quad(\%)$ & $\mathrm{NF}$ & $\begin{array}{c}\mathrm{CT} \\
(\mathrm{cm})\end{array}$ & $\begin{array}{c}\text { AP } \\
(\mathrm{cm})\end{array}$ & $\begin{array}{c}\mathrm{CR} \\
(\mathrm{cm})\end{array}$ & $\begin{array}{c}\text { DC } \\
(\mathrm{mm})\end{array}$ & $\begin{array}{c}\text { MMST } \\
(\mathrm{g})\end{array}$ & $\begin{array}{c}\text { MMSPA } \\
(\mathrm{g})\end{array}$ & $\begin{array}{c}\text { MMSR } \\
(\mathrm{g})\end{array}$ & NBP \\
\hline 'Alô Doçura' & $97,55 \mathrm{~ns}$ & $51,3 \mathrm{~ns}$ & $54,71 \mathrm{~ns}$ & $33,43 \mathrm{~ns}$ & $21,28 \mathrm{~ns}$ & $2,45 \mathrm{~ns}$ & $1,25 \mathrm{ab}$ & $1,13 \mathrm{ab}$ & $0,12 \mathrm{~ns}$ & $4,01 \mathrm{~b}$ \\
'Campinas 1' & 97,55 & 69,03 & 57,54 & 35,36 & 22,18 & 2,77 & $1,50 \mathrm{a}$ & $1,37 \mathrm{a}$ & 0,13 & $6,32 \mathrm{ab}$ \\
'Relíquia' & 100 & 76,75 & 62,25 & 36,23 & 26,02 & 2,88 & $1,46 \mathrm{a}$ & $1,31 \mathrm{a}$ & 0,15 & $6,88 \mathrm{a}$ \\
'Ouromel' & 100 & 71,57 & 60,51 & 35,43 & 25,08 & 2,56 & $1,19 \mathrm{ab}$ & $1,06 \mathrm{ab}$ & 0,13 & $5,21 \mathrm{ab}$ \\
'Josefina' & 99,38 & 63,44 & 54,71 & 33,05 & 21,66 & 2,41 & $0,95 \mathrm{~b}$ & $0,81 \mathrm{~b}$ & 0,14 & $4,10 \mathrm{~b}$ \\
\hline CV (\%) & 23,54 & 23,02 & 25,35 & 25,40 & 29,17 & 25,28 & 43,40 & 45,47 & 83,93 & 23,50 \\
\hline
\end{tabular}

ns. Não significativo pelo teste F.

*Letras diferentes na mesma coluna diferem significativamente ao nível de 5\% de probabilidade, pelo teste de Tukey. 
crescimento é resultado da atividade fotossintética, e o restante depende da absorção de nutrientes do substrato. Assim, supõe-se que o maior número de folhas por planta, obtido no substrato S1 (Plantmax $®)$, pode ter resultado em maior atividade fotossintética, o que favoreceu o maior acúmulo de matéria seca total e da parte aérea.

Os substratos Plantmax $®$ (S1) e Plantmax ${ }^{\circledR}+$ Areia (S2), apresentaram as maiores médias em relação ao comprimento total, diâmetro do caule e altura das plantas, contudo esses substratos não diferiram significativamente do substrato Plantmax ${ }^{\circledR}+$ Latossolo Vermelho (S3).

O maior desenvolvimento em altura, formação radicular e em diâmetro do caule, favorece a obtenção mais rápida de porta-enxertos aptos e pode antecipar o início da produção e abreviar o início da avaliação dos frutos.

Hartman et al. (1990) mencionam que os principais efeitos dos substratos manifestam-se sobre as raízes, podendo influenciar o crescimento da parte aérea. No caso deste experimento, os efeitos não foram significativos, sendo provável que o tempo de avaliação não tenha sido suficiente para melhor caracterização do efeito do substrato, que se manifestou mais no desenvolvimento da parte aérea.

Pode-se observar que o substrato S4 (Plantmax + Latossolo Vermelho + Areia) apresentou as menores médias nas variáveis que diferiram significativamente, supondo-se que os menores teores de P (Tabela 2) estejam relacionados ao menor desenvolvimento do porta-enxerto. Para Black (1967), o P é o elemento chave na fase inicial de crescimento por causa do maior acúmulo de biomassa nessa fase. Isso indica que a mistura Plantmax ${ }^{\circledR}+$ Latossolo Vermelho + Areia (1:1:1 v/v) não é aconselhável para o rápido crescimento inicial de pessegueiro.

Quanto às cultivares, somente observou-se efeito significativo na massa da matéria seca total e da parte aérea das plantas e, no número de brotações (Tabela 4).

No que se refere à massa de matéria seca total e da parte aérea das cultivares, as maiores médias foram obtidas com 'Campinas 1' e 'Relíquia', sendo que elas não diferiram significativamente dos pessegueiros 'Alô Doçura' e 'Ouromel'.

Para o número de brotações primárias obteve-se o maior resultado com o pessegueiro 'Relíquia', seguido pelas cultivares 'Campinas 1' e 'Ouromel', que não diferiram de 'Josefina' e 'Alô Doçura'. Acredita-se que isso pode estar relacionado à constituição genética de cada cultivar para obtenção de maior ou menor número de brotações primárias.

Martínez-Gómez \& Dicenta (2001) descrevem que o período de estratificação para sementes de pessegueiro tem influência no posterior desenvolvimento das plantas. Toit et al. (1979), estudando a necessidade do frio durante a dormência de sementes de pessegueiro 'Kakamas' obtiveram maior comprimento dos brotos, massa de matéria seca de brotos e raízes e área foliar, quando aumentou-se linearmente o tempo de estratificação.

Pelo fato das sementes dos cultivares estudados no presente trabalho terem sido submetidas as mesmas condições de estratificação, supõe-se que, mesmo apresentando necessidades de acúmulos de frio diferentes para sua germinação (Tabela 1), esse fator não interferiu durante o desenvolvimento inicial das plantas.

De maneira geral, o substrato Plantmax ${ }^{\circledR}(\mathrm{S} 1)$ proporcionou maior desenvolvimento inicial das plantas, embora não tenha havido diferenças significativas entre os substratos em algumas das características analisadas. Supõe-se que, isso se deva provavelmente, ao bom equilíbrio na composição desse substrato, proporcionando melhores condições para as plantas, em relação à aeração, nutrição, sustentação e retenção de umidade. Esse aspecto é de grande importância em trabalhos de pesquisa e também na produção comercial de mudas, assegurando-se, dessa forma a repetibilidade dos resultados.

O substrato teve efeito no desenvolvimento inicial do pessegueiro, obtendo-se os melhores resultados com o substrato comercial Plantmax ®.

O maior acúmulo de massa de matéria seca total e da parte aérea das plantas foi obtido com as cultivares 'Campinas 1' e 'Relíquia'.

\section{REFERÊNCIAS BIBLIOGRÁFICAS}

BARBOSA, W.; DALL'ORTO, F. A. C.; OJIMA, M.; MARTINS, F. P.; RIGITANO, O. Emergência de plântulas de pêssego porta-enxerto 'Okinawa': influência de períodos de estratificação e de ácido giberélico. Bragantia, Campinas, v. 46, n. 2, p. 435-441, 1987.

BLACK, C. A. Soil plant relationships. 2. ed. New York: J. Wiley, 1967. $792 \mathrm{p}$.

CHALFUN, N. N. J.; PASQUAL, M.; HOFFMANN, A. Fruticultura comercial: frutíferas de clima temperado. Lavras: UFLA-FAEPE, 1998. v. 7, 129 p.

FACHINELLO, J. C. Problemática das mudas de plantas frutíferas de caroço. In: SIMPÓSIO INTERNACIONAL DE FRUTAS DE CAROÇO, 1., 2000, Porto Alegre. Anais... Porto Alegre: UFRGS, 2000. p. 25-40.

FACHINELLO, J. C.; HOFFMANN, A.; NACHTIGAL, J. C.; KERSTEN, E.; FORTES, G. R. L. Propagação de plantas frutíferas de clima temperado. 2. ed. Pelotas: UFPel, 1995. $179 \mathrm{p}$. 
FERMINO, M. H. Aproveitamento de resíduos industriais e agrícolas como alternativas de substratos hortícolas. 1996. 90 f. Dissertação (Mestrado em Fitotecnia) - Universidade Federal do Rio Grande do Sul, Porto Alegre, 1996.

FINARDI, N. I. Métodos de propagação e descrição de porta-enxertos. In: MEDEIROS, C. A. B.; RASEIRA, M. C. B. A cultura do pessegueiro. Brasília, DF: Embrapa, 1998. p. 100-129.

FREIRE, C. J. S.; MAGNANI, M. Adubação e correção do solo. In: MEDEIROS, C. A. B.; RASEIRA, M. C. B. A cultura do pessegueiro. Brasília, DF: Embrapa-SPI; Pelotas: Embrapa-CPACT, 1998. p. 161-187.

HARTMANN, H. T.; KESTER, D. E.; DAVIES JUNIOR, F. T. Plant propagation: principles and practices. 5. ed. Englewood Cliffs: Prentice Hall, 1990. 642 p.

KÄMPF, A. N. Substrato. In: Produção comercial de plantas ornamentais. Guaíba: Agropecuária, 2000. 254 p.

KÄMPF, A. N. Substratos para floricultura. In: CASTRO, C. E. F. de; ANGELIS, B. L. D. de; MOURA, L. P. P. de. Manual de floricultura. Maringá: SBFPO, 1992. p. 36-43.

LARCHER, W. Ecofisiologia vegetal. São Carlos: Rima, 2000. $531 \mathrm{p}$.

MARTÍNEZ-GÓMEZ, P.; DICENTA, F. Mechanisms of dormancy in seeds of peach (Prunus persica (L.) Batsch) cv. GF305. Scientia Horticulturae, Amsterdam, v. 91, p. 51-58, 2001.

PEREIRA, F. M.; NACHTIGAL, J. C.; ROBERTO, S. R. Tecnologia para a cultura do pessegueiro em regiões tropicais e subtropicais. Jaboticabal: Funep, 2002. 62 p.

RAMOS, J. D.; CHALFUN, N. N. J.; PASQUAL, M.; RUFINI, J. C. M. Produção de mudas de plantas frutíferas por semente. Informe Agropecuario, Belo Horizonte, v. 23, n. 216, p. 64-72, 2002.

RICHARDSON, E. A.; SEELEY, S. D.; WALKER, D. R. A model for estimating the completion of rest for 'Redhaven' and 'Elberta' peach trees. HortScience, Alexandria, v. 1, p. 331-332, 1974.

SEELEY, S. D.; AYANOGLU, H.; FRISBY, J. W. Peach seedling emergence and growth in response to isothermal and cycled stratification treatments reveal two dormancy components. Journal of American Society for Horticultural Science, Alexandria, v. 123, n. 5, p. 776-780, 1998.

TOFANELLI, M. B. D.; ONO, E. O.; RODRIGUES, J. D. Método de aplicação de ácido indolbutírico no enraizamento de estacas herbáceas de pessegueiro. Revista Brasileira de Fruticultura, Jaboticabal, v. 25, n. 2, p. 363-364, 2003.

TOIT, H. J.; JACOBS, G.; STRYDOM, D. K. Role of the various seed parts in peach seed dormancy and initial seedling growth. Journal American Society Horticultural Science, Alexandria, v. 104, n. 4, p. 490-492, 1979.

TOLEDO, A. R. M. de. Efeitos de substratos na formação de mudas de laranjeira (Citrus sinensis (L.) Osbeck cv. Pera Rio) em vaso. 1992. 88 f. Dissertação (Mestrado em Fitotecnia) - Universidade Federal de Lavras, Lavras, 1992.

WAGNER JÚNIOR, A.; PIMENTEL, L. D.; NEGREIROS, J. R. S.; ALEXANDRE, R. S.; MORGADO, M. A. D.; SILVA, J. O.; BRUCKNER, C. H. Influência do estádio de maturação dos frutos e do substrato na formação de seedlings de três cultivares de pessegueiro. Revista Brasileira de Agrociência, Pelotas, v. 12, n. 2, p. 223-227, 2006.

ZONTA, E. P.; MACHADO, A. A.SANEST-Sistema de Análise Estatística para Microcomputadores. Pelotas: UFPel, 1984. 75 p. 
